\title{
AUDIODESCRIÇÃO E ACESSO À CULTURA AUDIOVISUAL PARA O EMPODERAMENTO DE PESSOAS COM DEFICIÊNCIA VISUAL
}

\author{
Marisa Ferreira Aderaldo* \\ Élida Gama Chaves**
}

\begin{abstract}
RESUMO
A cultura contemporânea é especialmente multimodal no sentido de que, para expressar-se, utiliza suportes variados como televisão, rádio, celulares, computadores etc, com emprego de diferentes linguagens e formatos. De modo a fazer um recorte nas linguagens associadas ao sentido da visão, este artigo procura focalizar determinada parcela da população, justamente aquela que, estando privada desse sentido (a pessoa com deficiência visual), carece de soluções que lhe possibilitem o usufruto e acesso à informação visual presente em espaços como cinemas, teatros, passeios turísticos etc. Um modo de compensar a ausência da visão e de tornar a imagem acessível é a audiodescrição, tratada neste artigo como tradução intersemiótica e audiovisual, pois traduz a informação visual em informação verbal (escrita ou oral).
\end{abstract}

Palavras-chave: Tradução audiovisual acessível. Audiodescrição. Pessoas com deficiência visual. Moça com brinco de pérola.

\section{ABSTRACT \\ AUDIO DESCRIPTION AND ACCESS TO AUDIOVISUAL CULTURE TO THE EMPOWERMENT OF VISUALLY IMPAIRED PEOPLE}

Contemporary culture is especially multimodal, in the sense that, to express itself makes use of various media, such as television, radio, cell phones, computers etc. through different languages and formats. In order to make a selection of languages associated with the sense of sight, this paper highlights specific part of population, just the ones (the visually impaired people), who has no means to enjoy and access visual information as cinema, theaters, travel tours etc. A way to compensate the lack of vision, and make images accessible is through audio description, that is treated here as intersemiotic and audiovisual translation ones, once it translates visual information into verbal information (written or oral).

Keywords: Accessible audiovisual translation. Audio description. Visually impaired people. Girl with a pearl earring.

* Doutora em Estudos da Tradução pela Universidade Federal de Minas Gerais (UFMG). Professora do curso de Letras do Centro de Humanidades da Universidade Estadual do Ceará (CH/UECE). Membro do Grupo de Pesquisa em Legendagem e Audiodescrição (LEAD/UECE). E-mail: marisauece@yahoo.com.br

** Doutora em Linguística Aplicada pela Universidade Estadual do Ceará. Professora da Faculdade de Educação, Ciências e Letras do Sertão Central da Universidade Estadual do Ceará (FECLESC/UECE). Membro do Grupo de Pesquisa em Legendagem e Audiodescrição (LEAD/UECE). E-mail: elidagama@hotmail.com 


\section{RESUMEN}

\section{AUDIODESCRIPCIÓN Y ACCESO A LA CULTURA AUDIOVISUAL PARA EL EMPODERAMIENTO DE PERSONAS CON DISCAPACIDAD VISUAL}

La cultura contemporánea es especialmente multimodal en el sentido de que, para expresarse, utiliza soportes variados como televisión, radio, celulares, computadoras etc, con empleo de diferentes lenguajes y formatos. Con el propósito de promover un recorte sobre los lenguajes asociados al sentido de la visión, en este artículo se busca focalizar determinada parte de la población, justamente aquella que, estando privada de ese sentido (la persona con discapacidad visual), carece de soluciones que le posibiliten el usufructo y acceso a la información visual presente en espacios como cines, teatros, paseos turísticos etc. Un modo de compensar la ausencia de la visión y de hacer la imagen accesible es la audiodescripción, tratada en este artículo como traducción intersemiótica y audiovisual, pues traduce la información visual en información verbal (escrita u oral).

Palabras clave: Traducción audiovisual accesible. Audiodescripción. Personas con discapacidad visual. La joven de la perla.

\section{Introdução}

Gramani, amigo rabequista. Rabeca é um violino portador de deficiência. Há muito violino fino sem deficiência que só desafina. Nas mãos do Gramani, uma rabeca feita de bambu gigante, deficiente, toca Bach. Pois assim são as pessoas. (ALVES, 1998, p. 39).

Em países como Estados Unidos, Espanha, Inglaterra, Alemanha, Japão, e mais recentemente o Brasil, cresce a consciência de que o preconceito e a exclusão social são faces de uma mesma moeda e que todo esforço coletivo é necessário para a construção de um modelo social sem barreiras.

Frequentar salas de cinema ou de teatro é um prazer que tem sido sonegado aos deficientes sensoriais, e a constatação é de que essas pessoas não são consideradas enquanto público. Em exibições audiovisuais, os cegos ou surdos, por exemplo, não são contemplados com medidas e recursos compensatórios que lhes permitam ter acesso aos produtos, o que os desestimula a compartilhar o mesmo espaço com o público vidente ou ouvinte.

Aos poucos, porém, à medida que a sociedade proclama sua compreensão sobre os direitos humanos e que aumentam as ações socioafirmativas mediante a promulgação de novas leis, bem como a otimização das tecnologias, as barreiras tendem a diminuir e aqueles produtos multissemióticos que até então estavam inacessíveis àquelas pessoas começam a tornar-se acessíveis para um usufruto sem exclusão.

Uma série de demandas relativas à acessibilidade no âmbito da produção audiovisual para cultura e lazer, foco deste trabalho, vem sendo amparada a partir de algumas medidas de natureza jurídica resultantes da pressão da sociedade. No âmbito governamental, por exemplo, foi aprovado o Estatuto da Pessoa com Deficiência, de autoria do senador Paulo Paim, denominado Lei Brasileira de Inclusão da Pessoa com Deficiência (Lei ${ }^{\circ} 13.146 / 15$ ), que determina, entre outras coisas, que as pessoas com deficiência têm direito à cultura em igualdade de oportunidades com as demais pessoas, sendo-lhes garantido o acesso aos bens culturais em formatos acessíveis. Segundo a lei, é vedada a recusa de oferta de acesso à obra intelectual, em formato acessível, à pessoa com deficiência, sob qualquer argumento, inclusive sob a alegação da proteção dos direitos de propriedade intelectual (BRASIL, 2015).

No tocante às salas de cinema, por exemplo, a lei prevê que sejam oferecidos, em todas as sessões, recursos de acessibilidade para as pessoas com deficiência visual e auditiva. Relativamente a essas deficiências, no que diz respeito a produções financiadas com recursos públicos federais geridos pela Agência Nacional do Cinema (Ancine), uma 
instrução normativa dispõe sobre normas gerais e critérios básicos de acessibilidade - a Instrução Normativa $\mathrm{n}^{\mathrm{o}} 116$, de 18 de dezembro de 2014 (BRASIL, 2014). Esta norma prevê que todas as produções audiovisuais do Brasil ofereçam uma cópia com os recursos de audiodescrição, legendagem para surdos e ensurdecidos e janela de interpretação de Libras.

Após a publicação da instrução normativa, o Ministério da Cultura, em parceria com uma equipe voluntária, composta por profissionais e pesquisadores atuantes na área da acessibilidade audiovisual, somou esforços na elaboração de um guia orientador destinado aos produtores culturais, diretores de filmes e gestores, com a finalidade de orientá-los a produzir e avaliar um produto no quesito "acessibilidade", não apenas para garantir o acesso a financiamentos e outras formas de apoio financeiro, mas também, e acima de tudo, para apresentar um produto que possa ter como público todos os interessados, sem oferecer barreiras que privem as pessoas com deficiência de desfrutar essas produções audiovisuais. O documento, elaborado pari passu com a consultoria de pessoas com deficiência, foi apresentado em audiência pública, em 2015, ${ }^{1}$ e lançado em outubro de 2016 pela Secretaria do Audiovisual do MinC, com apoio do Instituto de Letras da UnB. O texto oferece parâmetros para a elaboração de audiodescrição fílmica, legendagem para surdos e ensurdecidos (LSE) e janela de interpretação de Libras.

Este artigo focaliza apenas a audiodescrição (AD), que é, em poucas palavras, a tradução da informação visual em informação verbal. A audiodescrição é um recurso de acessibilidade que amplia o entendimento das pessoas com deficiência visual em eventos culturais, gravados ou ao vivo, como peças de teatro, programas de TV, exposições, mostras, musicais, óperas, desfiles e espetáculos de dança; eventos turísticos, esportivos, pedagógicos e científicos, tais como aulas, seminários, congressos, palestras, feiras e outros, por meio de informação sonora. É uma atividade de mediação linguística e modalidade de tradução intersemió-

1 O texto foi apresentado em Sessão Pública, na Plenária $n^{\circ} 7$ da Comissão de Defesa das Pessoas com Deficiência da Câmara dos Deputados (Brasília), em 18 de novembro de 2015, às 14 horas. tica (JAKOBSON, 2000), " "[...] que transforma o visual em verbal, abrindo possibilidades maiores de acesso à cultura e à informação, contribuindo para a inclusão cultural, social e escolar" (MOTTA; ROMEU FILHO, 2010, p. 07).

Embora a AD independa do suporte, ela é, ao mesmo tempo, subordinada a ele, de modo que é essencial pensar se o roteiro da audiodescrição vai circular em modo escrito, para ser lido em computador, gravado para ser ouvido ou se a apresentação será in presencia da pessoa com deficiência e do locutor, como é o caso da AD em teatros, excursões, conferências, aulas, visitas guiadas a museus e galerias etc.

O trabalho é uma reflexão acadêmica desenvolvida no âmbito do Programa de Pós-Graduação em Linguística Aplicada da Universidade Estadual do Ceará e Grupo de Pesquisa em Legendagem e Audiodescrição (Grupo Lead/LATAV) para apresentar duas propostas de acessibilidade visual de uma imagem exibida em dois diferentes suportes: bidimensional (estático) e audiovisual (dinâmico), para demonstrar que, para seguir a lei que propõe igualdade de oportunidades na oferta de um produto, é preciso pensar também na qualidade e na expertise daquele que elabora este serviço: o audiodescritor, profissão já regulamentada e incluída na Classificação Brasileira de Ocupações (CBO) com rubrica na área 2614 e subárea 2614-307, ${ }^{3}$ que considera como audiodescritor o roteirista, o consultor pessoa com deficiência visual e o locutor.

No tocante à expertise do audiodescritor roteirista e do audiodescritor consultor, Aderaldo (2014), cujo trabalho é a referência teórica deste artigo,

2 Conforme Plaza (1987), que partiu do conceito jakobsoniano, a tradução intersemiótica é uma operação na qual um texto pertencente a um sistema de signos - sonoro, verbal, visual etc. - é traduzido para outro sistema de signos. Com base nesse autor, Alves, Teles e Pereira (2011) reforçam a compreensão de que a AD é uma tradução intersemiótica, pois se caracteriza pela tradução de imagens (visual) em palavras (verbal).

3 Essa importante conquista, a profissionalização, é resultante do Projeto de Lei $\mathrm{n}^{\circ}$ 5.156, de 2013, de autoria do Sr. Eduardo Barbosa, que criou a profissão de audiodescritor dividida em três funções básicas: roteirista, revisor e consultor, sendo que este último deve ser, necessariamente, uma pessoa cega ou com baixa visão. "A profissão de audiodescritor passa a integrar como grupo a Confederação Nacional dos Profissionais Liberais a que se refere o art. 577 da Consolidação das Leis do Trabalho - CLT, aprovada pelo Decreto-lei $\mathrm{n}^{\circ} 5.452$, de $1^{\circ}$ de maio de 1943 ”, fragmento do Projeto de Lei n. ${ }^{\circ} 5.156$, de 2013, aprovado pela Câmara dos deputados (ADERALDO, 2016). 
considera que, por ser considerada uma tradução, a $\mathrm{AD}$ é o resultado de escolhas que não podem ser aleatórias e que carecem de justificativa, não sendo suficiente seguir a instrução "descreva o que você vê", corrente entre certos audiodescritores. Para a autora, é necessário fazer escolhas conscientes e criteriosas e, para orientá-las, Aderaldo (2014) desenvolveu um modelo semiótico para audiodescritores, em especial àqueles que se dedicam à audiodescrição de obras de arte bidimensionais (pinturas). O modelo em questão, em forma de parâmetros descritivos, é aplicado à leitura e análise da obra prima do pintor holandês Johannes Vermeer (1632-1675), seu famoso quadro conhecido como Moça com brinco de pérola, cujo retrato inspirou a novelista norte-americana Tracy Chevalier (1999) a escrever um romance ecfrástico - Girl with a pearl earring, ficção romantizada sobre a relação entre a modelo do retrato e o pintor. O livro foi adaptado à tela grande em 2003, com direção de Peter Webber, Scarlett Johansson no papel da protagonista Griet e Colin Firth como Vermeer, em filme homônimo (GIRL..., 2003).

A título de exemplo analítico-descritivo, as autoras deste artigo aplicam o modelo de Aderaldo (2014) à obra que é apresentada em dois diferentes suportes, tratando-se primeiramente da pintura abrigada no acervo do Museu Mauritius, na Holanda, e sua representação audiovisual no filme homônimo acima mencionado. Assim, na próxima subseção, é proposta uma $\mathrm{AD}$ para o que seria uma exibição em museu e outra para a obra referenciada no filme.

\section{Acessibilidade ao filme Moça com brinco de pérola por meio da AD}

O filme selecionado para esta apresentação é Girl with a pearl earring (Moça com brinco de pérola) doravante MCBP (GIRL..., 2003), o qual foi inspirado na famosa pintura que romanceia a identidade fictícia de uma jovem cujo olhar "enigmático" foi capturado por Johannes Vermeer (1632-1675), pintor do século de ouro da pintura holandesa, admirado pelo emprego das cores e do brilhante uso da luz.

Pouco se sabe da vida de Vermeer, apenas que morreu pobre e que sua viúva teria vendido os quadros em seu poder. Praticamente desconhecido nos séculos seguintes, foi reconhecido como grande pintor em 1866, graças a Theophile Thoré (pseudônimo de W. Burger), crítico de arte que lhe atribuiu uma série de pinturas. $\mathrm{O}$ mistério sobre a vida do pintor holandês contribui para aumentar a aura que envolve suas pinturas hoje em dia, a mesma que se sente ao ler a obra de Tracy Chevalier (1999) e ao assistir ao filme que dela deriva.

Figura 1 - Capa do DVD do filme A moça com brinco de pérola

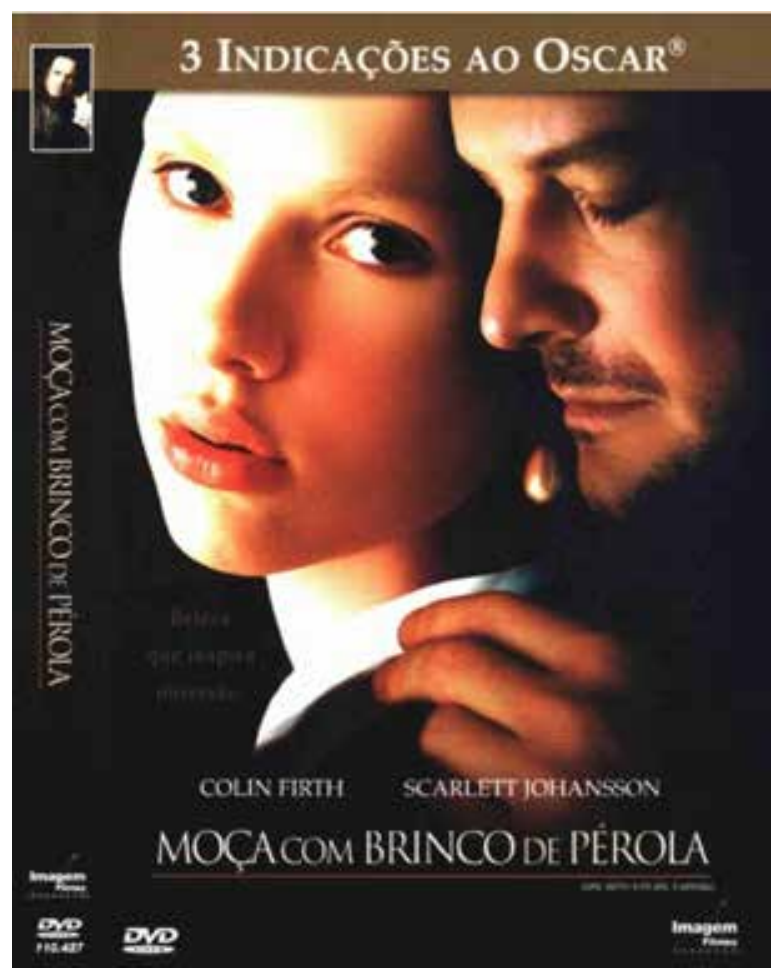

Fonte: Adoro Cinema (2016).

Em pleno século XVII vive Griet (Scarlett Johansson), uma jovem camponesa holandesa. Devido a dificuldades financeiras, Griet é obrigada a trabalhar na casa de Johannes Vermeer (Colin Firth), um renomado pintor de sua época. Aos poucos Johannes começa a prestar atenção na jovem de apenas 17 anos, fazendo dela sua musa inspiradora para um de seus mais famosos trabalhos: a tela Girl with a Pearl Earring. (ADORO CINEMA, 2016).

Antes da elaboração dos respectivos roteiros de ADs, conforme informamos anteriormente, as imagens foram analisadas por meio dos parâmetros descritivos que Aderaldo (2014) desenvolveu para 
a instrumentalização e letramento visual artístico de audiodescritores, conforme o Quadro 1.

\section{Parâmetros descritivos para instrumentalização de audiodescritores}

O modelo semiótico de Aderaldo (2014), cujas teorias de base são a multimodalidade e a semiótica social, concebe a linguagem humana organizada em três funções universais: a função representacional (ou ideacional), cujo fim é transmitir informações sobre a realidade; a função modal (ou interpessoal), que visa, principalmente, promover a interação entre os usuários da linguagem, o que pode ser feito por meio do interesse que esta desperta; e a função composicional (ou textual), que tem por finalidade estruturar o texto de forma coerente e a partir da qual fazemos nossas escolhas para construir textos coesos e coerentes.

A autora parte, inicialmente, de um modelo semiótico elaborado por Michael O’Toole (1995, 2011), crítico de arte que percebeu a dificuldade que as pessoas leigas apresentavam ao serem colocadas diante de uma obra de arte. Pensando nesse público espectador leigo, mas amante da arte, o autor elaborou um modelo simplificado a partir do qual entendia que todas as pessoas seriam capazes de aprender a contemplar uma pintura com autonomia - sem depender de historiadores ou críticos de arte. Mediante um modelo semiótico trifuncional, organizou o modelo em dois eixos: o do sintagma, para analisar a estrutura de uma obra de arte em suas partes chamadas de unidades; e o eixo do paradigma, para analisar os sistemas realizados pelo artista a partir de suas escolhas.

Desse modo, segundo O'Toole, o espectador se capacita a identificar, com autonomia, certas escolhas realizadas no âmbito das cores, do enquadramento, do foco, da perspectiva e de um expressivo conjunto de sistemas como tamanho, alinhamento etc., os quais poderiam passar inadvertidos aos olhos de espectadores videntes e leigos.

A partir do modelo otooleano, Aderaldo (2014) desenvolveu, em sua tese de doutorado, um modelo semiótico que expande aquele proposto por O'Toole $(1995,2011)$, com outra finalidade e para outro público-alvo. Diferentemente daquele, que visava instrumentalizar um público vidente e leigo, Aderaldo (2014) visa ao público com deficiência visual e os respectivos tradutores da imagem - os audiodescritores, que escrevem roteiros de audiodescrição para compartilhar, em modo verbal (oral ou escrito), a imagem de uma obra de arte oferecida apenas em modo visual.

Considerando que muitos audiodescritores não têm letramento visual artístico e menos ainda experiência em analisar obras de arte bidimensionais (pinturas etc.), a autora desenvolveu uma proposta descritiva que objetiva despertar o olhar do observador para que este possa selecionar as informações criteriosamente e escrever o roteiro de $\mathrm{AD}$, o qual, em um segundo momento, deverá ser revisado por um consultor com deficiência visual, igualmente instrumentalizado pelo modelo, antes de compartilhar a imagem mediante a audiodescrição. Os passos propostos são os seguintes:

\section{A partir da imagem:}

\section{Roteirista vidente aplica modelo semiótico de Aderaldo (2014)}

\section{Roteiro provisório}

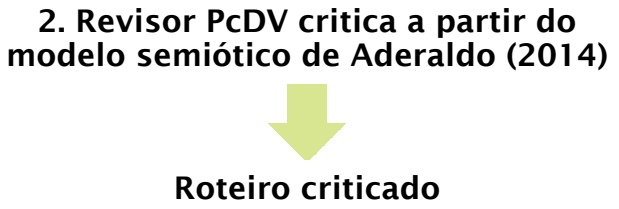

3. Ambos, roteirista e revisor, definem AD

Roteiro definitivo

4. Público PcDV 4

4 É interessante, mas não compulsório, que eles ofereçam feedback e que retroalimentem a $\mathrm{AD}$. 
O modelo semiótico de Aderaldo (2014), apresentado a seguir, contempla duas etapas. $\mathrm{Na}$ primeira, a autora propõe que a obra (a pintura) seja segmentada metodologicamente em unidades (obra, figura e conjuntos de figuras e membros), cujas partes formam o eixo sintagmático e es- trutural e, a partir das unidades, que estas sejam analisadas pelas funções representacional, modal e composicional, sendo livre a escolha da unidade e da função para o início da análise. As funções constituem o eixo paradigmático, isto é, o eixo relativo às escolhas que serão realizadas pelo artista.

Quadro 1 - Modelo semiótico de leitura de imagens artísticas

Gênero: Figurativo / Não figurativo (Abstrato)

Hierarquia clássica dos gêneros na pintura

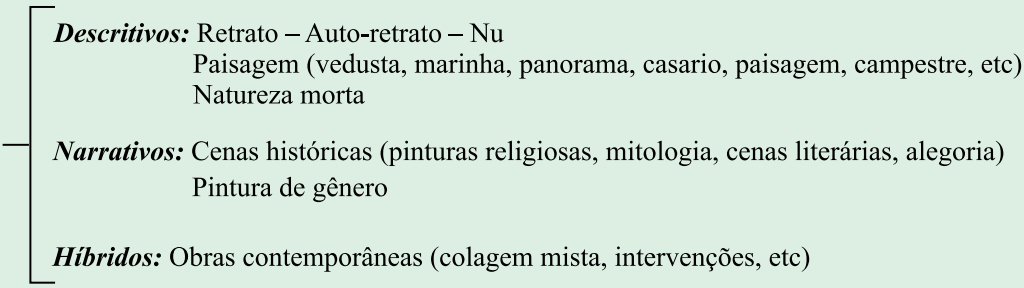

Escola / movimento / estilo: Renascimento - Barroco - Impressionismo - Expressionismo - Surrealismo - Cubismo Pop Art - Grafismo - Construtivismo - Op Art - Intervenção, etc.

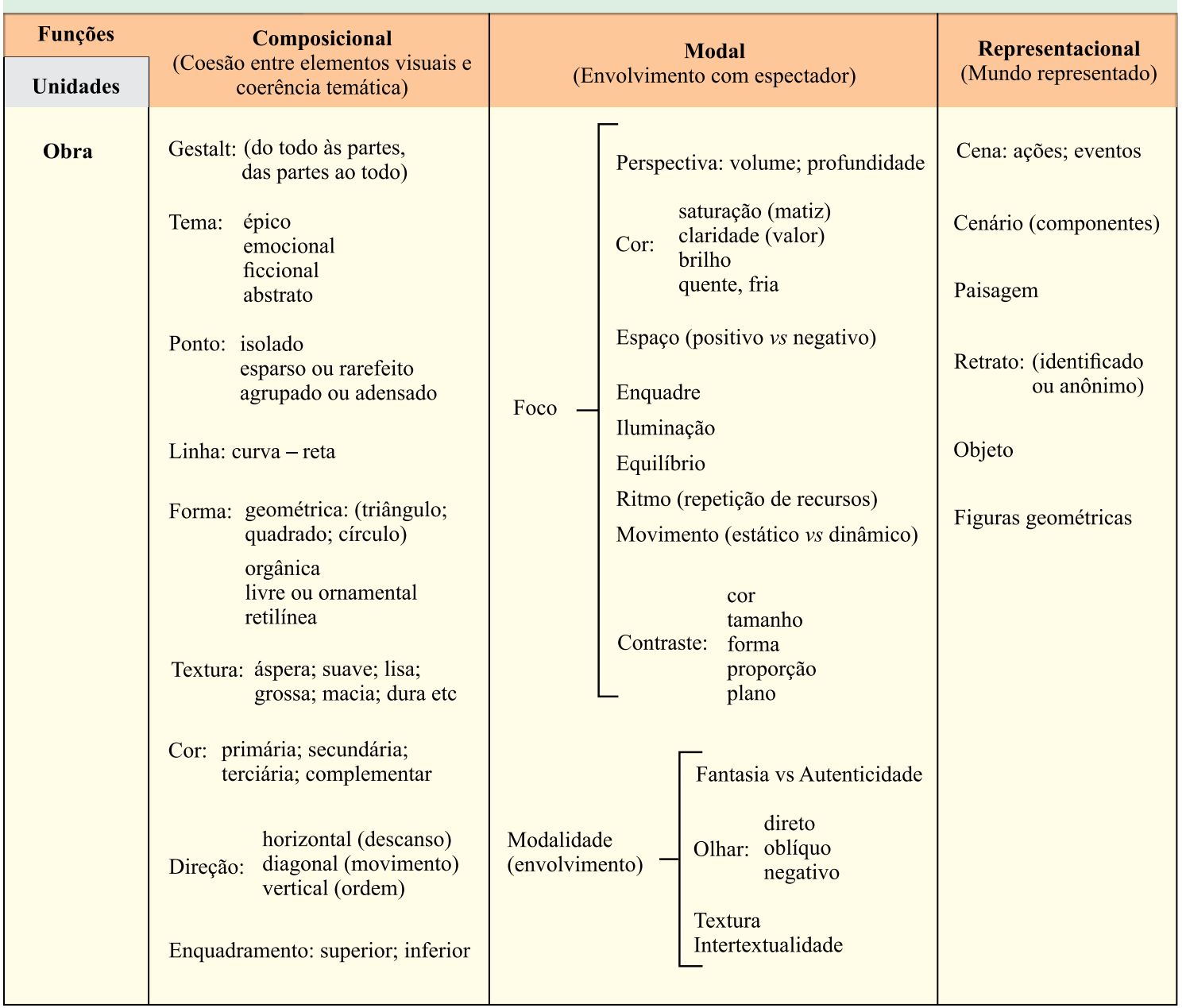




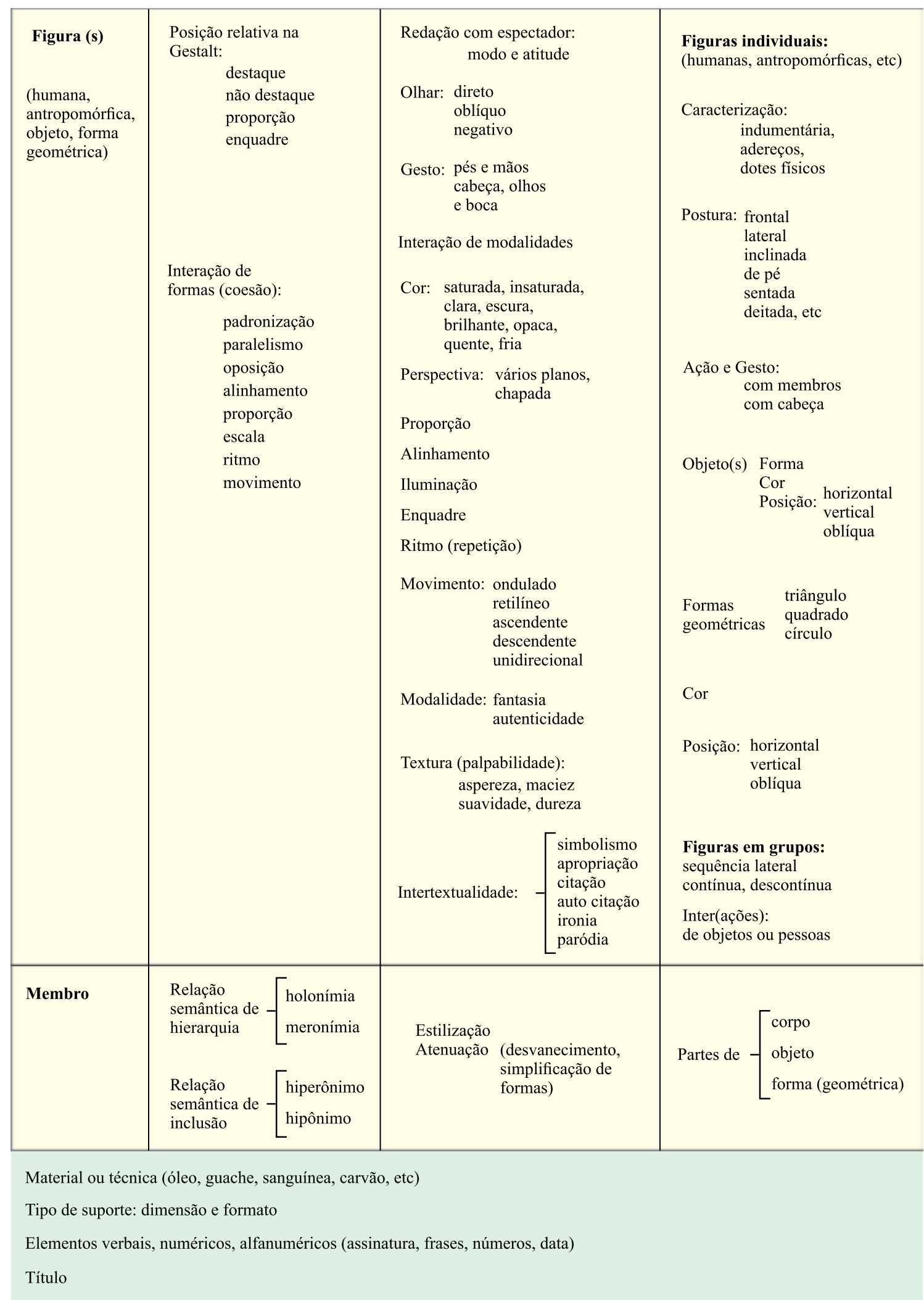

Fonte: Aderaldo (2014, p. 180-183). 
Para ajudar na percepção da obra, a autora formulou uma espécie de checklist, com perguntas de sensibilização prévia, por meio das quais o espectador audiodescritor começa a aproximar-se do conjunto da imagem, como podemos observar no Quadro 2.

Quadro 2 - Funções da linguagem na imagem artística bidimensional

\begin{tabular}{|c|c|}
\hline $\begin{array}{c}\text { Função } \\
\text { Composicional }\end{array}$ & $\begin{array}{l}\text { Há predomínio de linhas, formas ou cores? } \\
\text { Existem formas geométricas? Humanas? Zoomórficas? } \\
\text { As cores são distribuídas por peso cromático? } \\
\text { As cores demarcam espaços físicos ou sugerem temporalidade? } \\
\text { De que modo os espaços estão ocupados? No centro, laterais, superior ou } \\
\text { inferior? Há espaço negativo? } \\
\text { As figuras formam agrupamentos? De que modo as figuras se inter- } \\
\text { relacionam? Que tipo de identificação existe entre as figuras (ou objetos): } \\
\text { classe, tamanho, forma, cor? } \\
\text { Existem relações de nexo entre os elementos? } \\
\text { Os elementos se relacionam por simetria, paralelismo ou por oposição? }\end{array}$ \\
\hline Função Modal & $\begin{array}{l}\text { Entre possíveis elementos dominantes (foco), algo ou alguém se destaca dos } \\
\text { demais pelo posicionamento, pela cor ou pelo tamanho? } \\
\text { Existem elementos modais no antifoco? } \\
\text { As cores sugerem forma ou textura? Sugerem sensação física? } \\
\text { As cores estão relacionadas às emoções? } \\
\text { O olhar é oblíquo, direto, compartilhado entre os componentes ou é do tipo } \\
\text { olhar negativo? } \\
\text { É possível definir o vetor do olhar das figuras? } \\
\text { Há informações que dependem do conhecimento enciclopédico do } \\
\text { observador (intertextualidade)? }\end{array}$ \\
\hline $\begin{array}{c}\text { Função } \\
\text { Representacional }\end{array}$ & $\begin{array}{l}\text { A imagem é abstrata ou figurativa? } \\
\text { Quem ou o que está representado? } \\
\text { São figuras humanas? Abstratas? Antropomórficas? } \\
\text { As figuras são naturalistas como nas fotos ou não? } \\
\text { Há ordenação explícita entre as figuras representadas? De que lado começa } \\
\text { uma possível narrativa? } \\
\text { Existe alguma pista sobre a época e o lugar da representação? Qual? O } \\
\text { cenário contribui para informar dados sobre a cultura representada? } \\
\text { Alguém está fazendo algo? } \\
\text { É possível identificar "estados de ânimo" pelas expressões faciais ou } \\
\text { gestuais? Trata-se de parte significativa em relação ao todo? Por quê? } \\
\text { As cores estão relacionadas a algum tipo de representação (bandeiras, } \\
\text { flâmulas, códigos de trânsito, identidade étnica etc.)? }\end{array}$ \\
\hline $\begin{array}{l}\text { Aproximação ao } \\
\text { mundo da PcDV }\end{array}$ & $\begin{array}{l}\text { Quais qualidades como tamanho, forma e cor podem ser comparadas a } \\
\text { elementos do mundo da PcDV? } \\
\text { Quais percepções sensoriais, como tato e temperatura, podem ser agregadas } \\
\text { à tradução verbal da imagem? }\end{array}$ \\
\hline $\begin{array}{l}\text { Elementos } \\
\text { intratextuais }\end{array}$ & $\begin{array}{l}\text { Como podem ser explorados elementos verbais como título? } \\
\text { Palavras, letras, números, data e assinatura são abordados como elementos } \\
\text { intratextuais? }\end{array}$ \\
\hline Qualidades materiais & Como podem ser abordadas a matéria, a técnica e o suporte? \\
\hline
\end{tabular}

Fonte: Aderaldo (2014, p. 179). 


\section{Metodologia}

A imagem selecionada para ilustrar este artigo é Moça com brinco de pérolas, como se vê na Figura 2, conforme mencionado anteriormente. Inicialmente, a imagem foi submetida a um processo informático de inversão de cores, como vemos na Figura 3, com auxílio do programa editor de

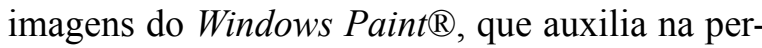
cepção da distribuição composicional das cores, dado o resultado quase bicromático na inversão. Assim, onde existem cores frias ou quentes, claras ou escuras, o efeito de redução nas cores contribui, empiricamente, para salientar que determinados sistemas como o foco, a iluminação, o peso visual etc. fiquem mais evidentes quando são vistos nessa espécie de "raio-x" da imagem. A inversão de cores é opcional, mas Aderaldo (2014) a aplica em outras ADs, com resultado satisfatório, para proporcionar a observação seletiva.

\section{Figura 2 - Pintura Moça com brinco de pérola}

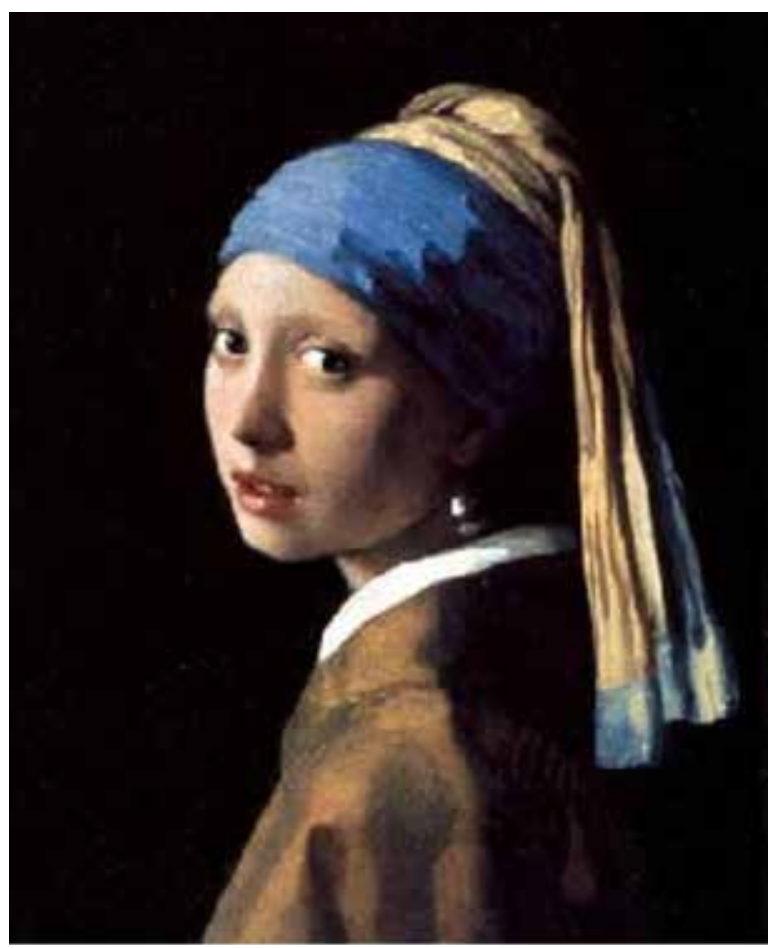

Fonte: Mauritshuis (2017).

Abaixo, na Figura 3, podemos observar o tratamento informático que altera as cores e a segmentação de acordo com a regra dos terços.
Figura 3 - Tratamento informático de inversão de cores e regra dos terços

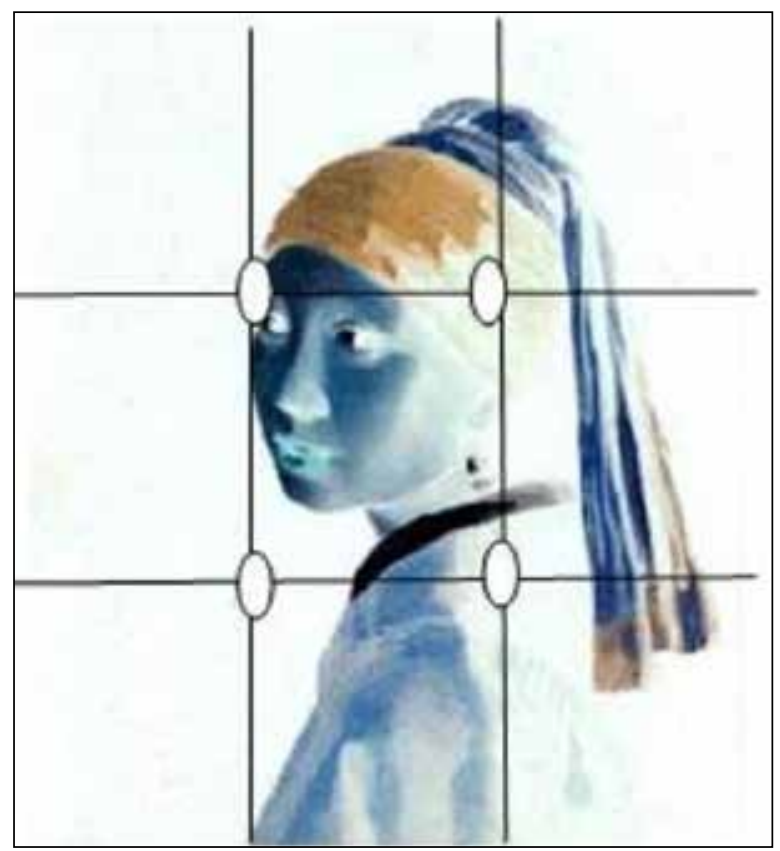

Fonte: Adaptado pelas autoras deste artigo a partir de Mauritshuis (2017).

Apenas a título de exemplo, para mostrar a eficácia da alteração de cores para o audiodescritor, a pequeníssima gola branca, que poderia passar inadvertida no conjunto da pintura, passou a chamar atenção ao destacar-se como linha divisória entre rosto e corpo, detalhe essencial na descrição da indumentária.

Além da alteração nas cores, a análise se ampara na segmentação em nove retângulos idênticos, conhecida como "regra dos terços", adaptada da proporção áurea $(\varphi)$, medida presente na natureza e descoberta pelo matemático grego Euclides, há 2.300 anos, também chamada pelos artistas renascentistas de "divina proporção". A simplificação na regra dos terços, que sequer chega a ser exatamente uma regra, é muito utilizada na atualidade pelos fotógrafos e foi empregada no passado por grandes artistas como Leonardo da Vinci, Salvador Dalí, Mondrian etc. Basicamente, na regra dos terços, $o$ tema ou aspecto a ser destacado posiciona-se entre os pontos de intersecção, chamados pontos áureos, como vemos na Figura 3.

Também como parte do modelo semiótico elaborado a partir do eixo da estrutura em uni- 
dades fixas (obra, figura ou conjunto de figuras e membros), a autora recomenda que a imagem seja segmentada, se possível, da maior à menor, não obstante o audiodescritor poder começar pela segmentação a partir da menor unidade (membro). Um exemplo de membro seria o brinco ou os olhos. No caso de MCBP, a segmentação em membros (útil também para objetos) acentua o cuidado com certos detalhes que o artista realiza - e que nem sempre estão perceptíveis aos espectadores sem o olhar perscrutador.

Como modo de realizar a análise semiótica, procuramos responder as questões sugeridas a partir do Quadro 2: Quem ou o que está representado? As figuras são naturalistas como nas fotos ou não? O olhar é oblíquo, direto, compartilhado entre os componentes ou é do tipo olhar negativo? É possível definir o vetor do olhar das figuras? Há predomínio de formas ou cores?

Em relação ao plano da imagem, o retrato foi tomado em ângulo de três quartos, em plano close up, como vemos na Figura 2, do ombro para cima, um recurso da linguagem visual que busca conferir certa intimidade com a retratada. Pela posição de seu corpo e de seus ombros, em quase perfil para quem a vê, podemos dizer que a jovem se oferece parcialmente à contemplação, embora o rosto voltado à esquerda, com um olhar enviesado, parece encarar o espectador de modo ambíguo, entre o malicioso e o ingênuo.

A análise, em detalhes, não é reproduzida neste artigo, em razão do espaço limitado, entretanto, informamos que tomamos a unidade "membros" e a analisamos à luz da função composicional e modal, no sistema "cor" e subsistema "saturação", "claridade", "brilho" e "quente/fria". Como resultado da leitura, observamos que o foco das cores em tons claros e mais luminosos recai sobre a faixa, à guisa de turbante e enrolada à moda turca, para ocultar os cabelos da modelo e deixar à mostra apenas seu brinco igualmente claro e brilhante, como vemos na Figura 2. Ainda sobre as cores, podemos perceber um nítido contraste entre as cores azul e amarela (primárias), a revelar a opção do pintor pela composição cromática como elemento estruturante e expressivo: o elemento azul conduz o olhar do espectador tanto para cima (no topo da cabeça) como para baixo (nas pontas do turbante), separados por uma linha branca (gola) que funciona como enquadre, separando a cabeça do tronco. $\mathrm{O}$ elemento de luz e brilho também está presente no eixo imaginário que alinha (sistema "alinhamento"), obliquamente, o olho esquerdo ao brinco de pérola grande, reluzente e em formato de gota, na orelha esquerda, como se pode ver na Figura 4. Consideramos que esses detalhes da linguagem artística são relevantes para a $\mathrm{AD}$, tanto pelo jogo das cores no turbante, como pelo enquadramento central do brinco, a reiterar sua importância na composição do quadro e no efeito modal que deve provocar na percepção do espectador.

Figura 4 - Eixo diagonal imaginário entre pontos de luz e brilho semelhantes

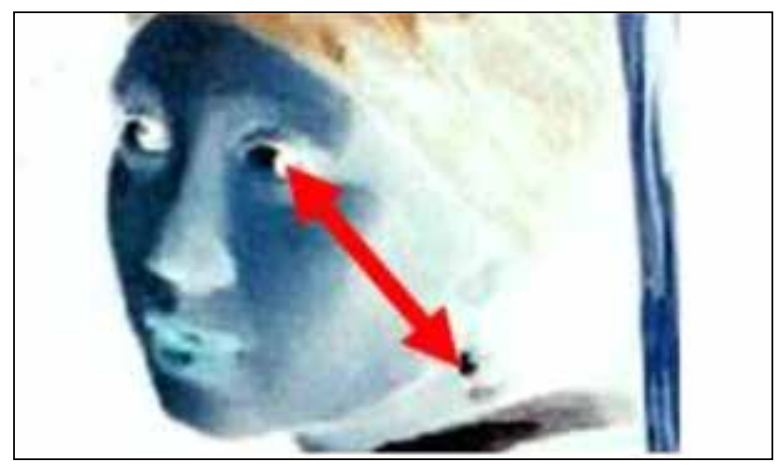

Fonte: Adaptado pelas autoras deste artigo a partir de Mauritshuis (2017).

Seguindo os sistemas disponíveis no modelo semiótico (ver Quadro 1), percebemos o foco de luz que se expande sobre a face, ilumina o alto da cabeça, o colo e a cauda do turbante deslocado para o lado esquerdo do ombro (sistema foco/ função modal/unidade obra). Em contraste à luz, o fundo totalmente escuro do quadro promove uma impressão visual que dá relevo ao rosto da personagem, isto é, a intensa luminosidade vinda pelo lado esquerdo da tela confere uma perspectiva tridimensional ao rosto.

O jogo claro/escuro tem como objetivo criar a tensão sobre o rosto e sobre pequenos detalhes como os adornos. A claridade obtida por um facho de luz imaginário, vindo pela esquerda da tela, lança luzes sobre parte de seu rosto, sobre o alto de seu turbante e sobre a cauda do turbante. O colo, coberto por um manto em tons escuros, cor terrosa, também recebe intensa luminosidade na parte 
dianteira. É de fundamental relevância informar, na audiodescrição, a presença do contraste claro e escuro, de modo que o deficiente visual possa formar uma imagem mental essencial sobre a pintura e empoderar-se no letramento visual artístico do estilo dessa pintura, o barroco.

Outra questão relevante é a linguagem corporal e, em especial, a linguagem facial. As pessoas com deficiência visual nem sempre são informadas de que o corpo também fala, conforme podemos ver nessa pintura, e que cabe a quem vê interpretar o que a jovem está insinuando com seus os lábios carnudos, ligeiramente entreabertos, e seu olhar, entre malicioso e ingênuo, certa ambiguidade que perpetua entre os admiradores da obra de Vermeer. $\mathrm{Na}$ interpretação ocidental, os lábios semiabertos dão certa sensualidade ao sorriso da jovem, ao mesmo tempo em que lhe dá um ar misterioso, tentando o espectador a perguntar-se: a quem e por que sorri? Todos esses aspectos - lábios carnudos, olhar dirigido ao observador etc. - são sistemas que foram realizados pelo pintor. Suas escolhas, capturando-as em plano close up, ou primeiríssimo plano, promovem impacto no espectador vidente, que deve compartilhá-lo mediante a $\mathrm{AD}$, destacando as informações que se referem à linguagem facial ocidental.

Feita a análise minuciosa da imagem, propomos a audiodescrição do quadro de Vermeer com base nos resultados obtidos através dos parâmetros de Aderaldo (2014). Após a análise, chega o momento das escolhas do audiodescritor para elaborar o roteiro da $\mathrm{AD}$ e submetê-lo à posterior leitura do revisor PcDV. Ambos os audiodescritores (roteirista e revisor consultor) devem estar conscientes de que não há - e nem pode haver - prescrição quanto ao tempo ou tamanho de um roteiro de audiodescrição de imagem estática, diferentemente da AD fílmica, que está subordinada entre diálogos. Entretanto, o bom senso, o escopo e o público-alvo são critérios úteis para roteirizar uma $\mathrm{AD}$ que não provoque cansaço e que, ao contrário, estimule a pessoa cega a voltar quantas vezes queira ao texto descritivo.

O texto a seguir é o roteiro da audiodescrição, o qual, posteriormente, poderá ser oralizado mediante voz humana ou artificial, tema que escapa ao escopo deste artigo, mas que abre inúmeras questões no âmbito da maior ou menor expressividade na AD.

\section{Roteiro de Audiodescrição da pintura}

A pintura se chama $A$ moça com brinco de pérola $\mathrm{e}$ foi pintada por Johannes Vermeer entre 1665 e 1667.

Está atualmente no Museu Mauritshuis, em Haia, na Holanda.

Mede 46,5 $\mathrm{cm}$ de altura por $40 \mathrm{~cm}$ de largura. Uma jovem é retratada até a altura dos ombros e parece uma fotografia naturalista, sem nenhum cenário.

$\mathrm{O}$ rosto iluminado de uma jovem clara contrasta com o fundo totalmente escuro. Os cabelos estão totalmente ocultos por um turbante em cores azul ultramarino e amarelo, enrolado à moda turca, com uma cauda pendente. Não sabemos como está totalmente vestida e podemos ver apenas parte de seu ombro coberto por um manto rústico, em tons de terra, sobre uma faixa branca que parece ser a gola de roupa interior.

Está em perfil, mas o rosto está voltado sobre o ombro esquerdo e seu olhar enviesado se encontra com nosso olhar, como a convidar-nos a entrar na obra. Os lábios, ligeiramente abertos, são carnudos e brilham com o batom avermelhado. Em sua orelha esquerda pende um grande brinco de pérola em formato de gota. A assinatura IVMeer se situa no extremo superior esquerdo da tela.

Sobre a AD da pintura cabe uma informação adicional, relativa à ordem de informação. Ainda que faltem teorias sobre a parte linguística desse gênero textual, entendemos que um texto coerente com a imagem deve seguir uma coesão entre os elementos vistos de forma ordenada. Assim, sem estar propondo nenhuma prescrição sequencial, nesta $\mathrm{AD}$ foi seguida a ordem: Gestalt (todo) ou visão geral inicial e sistemas realizados como tamanho, matéria e motivo. Detalhamento das partes (unidades), primeiramente a cabeça e o tronco, como uma unidade maior e, posteriormente, em mais detalhes, a parte central já analisada entre os pontos de ouro: os membros olhos, boca e orelha (ver Figura 3).

Trouxemos para a AD uma informação que consideramos importante a respeito da especificidade da cor azul ultramarino, pois Vermeer (assim como outros pintores de sua época) perseguia a mistura de materiais para obter um amplo espectro de cores. $\mathrm{O}$ denominado azul ultramarino era obtido pela pedra lápiz lázuli moída, material muito caro à época e 
diferenciador do status entre os mecenas de então.

A informação sobre essa cor a um deficiente visual não é um detalhe supérfluo; trata-se de trazer um contexto de cultura em que o azul ultramarino, em particular, aparece em outros quadros do pintor. Acreditamos que esse tipo de informação faz parte do letramento visual artístico, do conhecimento enciclopédico e que pode motivar o deficiente visual a buscar informações complementares, desenvolvendo novos hábitos culturais. Embora muitas pessoas se perguntem da necessidade de informar as cores às pessoas cegas, é importante recordar que todos vivemos em um mundo carregado de informações sobre cores, ainda que muitas não as vejam. Como diz Mianes (2016), a ausência da visão não os exclui de viver em um mundo colorido e dentro de uma sociedade que usa as cores como códigos de linguagem.

Feita a análise da pintura, ela serviu de base para orientar a roteirização da AD fílmica; porém, tratando-se de duas diferentes semioses, é importante também levar em conta as especificidades da linguagem fílmica, restrita no espaço/tempo pela natureza do audiovisual.

\section{A audiodescrição no filme}

As ADs fílmicas, em geral, são inseridas na banda sonora entre diálogos ou espaços silenciosos, como é o caso do filme Moça com brinco de pérola, em que a imagem da personagem Griet, que posava para o personagem Vermeer, vai desaparecendo e, aos poucos, vai surgindo, silenciosamente, a bela jovem retratada pelo holandês. Selecionamos alguns fragmentos da cena final para audiodescrevê-la, tendo em mente uma audiência de pessoas com deficiência visual. Ressaltamos que não foram levados em conta para essa atividade os variados níveis de deficiência e que não testamos o resultado estatisticamente para este artigo. ${ }^{5}$

O filme tem duração de 1 h40, porém, para esta apresentação, fizemos uma audiodescrição baseada nos 2 minutos finais, a qual foi possível com auxílio da ferramenta Subtitle Workshop $6.0 \mathrm{~b}$ (ver Figura 5). Esta ferramenta é de grande valia para audiodescritores, pois permite alcançar uma perfeita sincronia entre imagem e tradução verbal.

Figura 5 - Interface do programa Subtitle Workshop 6.0b

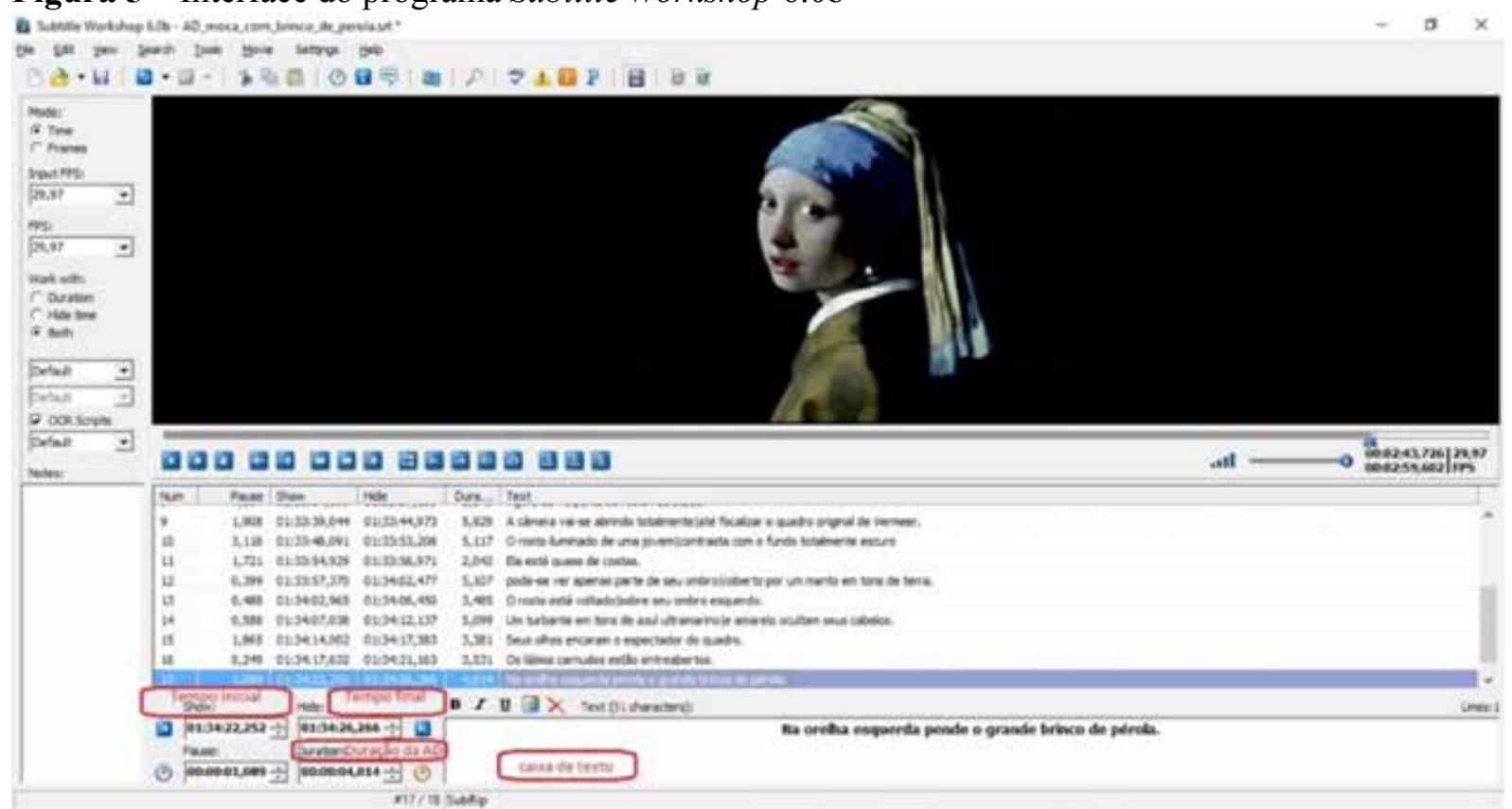

Fonte: Elaborado pelas autoras deste artigo.

5 Na oportunidade, queremos agradecer a Geovanio Ferreira da Silva, deficiente visual que colaborou com comentários críticos a respeito da $\mathrm{AD}$ do filme. 
Na Figura 5 podemos visualizar a interface do programa Subtitle Workshop $6.0 b .{ }^{6}$ Os procedimentos de marcação e tradução podem ser controlados à medida que o filme é reproduzido: o tempo inicial indica o momento em que a audiodescrição deve começar e o tempo final indica o momento em que ela deve parar. A duração de cada audiodescrição também pode ser visualizada e controlada. ${ }^{7}$

O programa possui uma caixa de texto e conta com menus variados que facilitam os processos de redação e revisão das traduções, as quais podem ser salvas em 56 formatos distintos. Entretanto, o formato ideal para salvar o roteiro de audiodescrição é o 'srt'. Este arquivo srt, quando aberto com o editor de texto "Bloco de Notas", permite uma clara visualização dos elementos fundamentais de um roteiro de audiodescrição, pois marca o tempo inicial e o final. Para finalizar o roteiro, basta ajustar o arquivo srt em uma tabela do Bloco de Notas do programa.

$\mathrm{O}$ fragmento do filme mostra uma sequência cronológica e dinâmica que, obviamente, não está mostrada na pintura. Na cena, a personagem Griet está em uma cozinha, pois era criada do pintor. Ali, ela recebe um embrulho que contém dois brincos de pérola. Ao recebê-los, sua imagem é sobreposta, paulatinamente, pela imagem da pintura. Ambas as personagens têm a mesma roupa e o mesmo brinco, informação que deverá levar a pessoa com deficiência pessoal a inferir e interpretar que se trata, em verdade, da jovem criada e seu retrato, uma modalidade denominada tronie porque não se tratava de retrato de pessoas ricas e importantes, ao contrário, o tronie retratava, em geral, rostos anônimos.

Segue a audiodescrição:

\section{Roteiro de audiodescrição fílmica}

Griet recebe um pequeno embrulho selado. Abre-o cuidadosamente. Vê um par de brincos de pérola. Pensativa, fecha o embrulho. Olha para algum lugar da casa. Tela escurece.

6 O programa Subtitle Workshop é um editor de legendas gratuito, produzido pela URUWorks, que se revelou ferramenta eficaz para a produção de roteiros de audiodescrição porque a interface do programa possibilita a visualização simultânea do arquivo de vídeo com as traduções e suas marcações de tempo inicial e final.

7 As audiodescrições aqui apresentadas foram produzidas obedecendo a razão 160 palavras por minuto, conforme parâmetro de velocidade de leitura utilizado pelo grupo LEAD-UECE.
Surge um ponto luminoso. Em destaque, um brinco de pérola na orelha e a boca vermelha, carnuda, entreaberta.

As pontas amarelas e azuladas de um turbante. Um rosto em perfil e o olhar profundo, meio risonho e meio insinuante de uma jovem a nos encarar. Usa um manto marrom com gola branca de roupa interior.

É curioso notar que a apresentação da imagem no filme segue o caminho inverso à $\mathrm{AD}$ da pintura. Enquanto naquela o início ocorre pela descrição gestáltica, a obra inteira e depois suas partes em detalhes, no filme a imagem se inicia pelas partes para chegar ao todo, a corroborar a importância de que o audiodescritor deve saber exatamente como fazê-lo.

A locução com $\mathrm{AD}$ desse trecho do filme foi gravada com auxílio de microfone e do programa editor de áudio Soundbooth. Em seguida, foi inserida no vídeo com auxílio do programa editor de vídeo Premiere, ambos programas profissionais do pacote Creative Suite (CS4) da Adobe, ${ }^{8}$ utilizados pelo grupo LEAD, no Laboratório de Tradução Audiovisual (LATAV) da UECE. Para a oralização existem várias possibilidades: o locutor da audiodescrição (que nem sempre coincide com as funções de audiodescritor ou tradutor) a lê, guiando-se pelo roteiro que respeita a duração do espaço possível de inserção entre diálogos.

Nesse caso, há uma longa cena silenciosa que se inicia desde a entrega dos brincos, em 01:31:40 (1 hora, 31 minutos e 40 segundos), até o aparecimento em zoom da pintura e a voz em off, que anuncia o nome da pintura e de seu pintor, em 01:39:58. É nesse intervalo, em 01:32:36, que, em nosso modo de ver, deve iniciar-se a AD, com duração média de 40 segundos, para preservar o som não diegético e o longo silêncio desejado pelo diretor do filme. É conveniente recordar que, poucos minutos antes, o quadro verdadeiro já havia surgido rapidamente, no intervalo de 01:31:10 a 01:31:18, na cena em que o rico mecenas está pensativo diante da tela. Aqui, a AD poderia ser mínima: "o comerciante aprecia o quadro de uma jovem com turbante e brinco de pérola", pois o importante é a inferência ao final.

8 Conjunto de programas editores de áudio e vídeo da empresa Adobe Systems. 


\section{Os limites da tradução: existe neutralidade na língua?}

Por último, e não menos importante, trazemos a questão apontada anteriormente sobre o clichê "descreva o que se vê", que circula entre certos audiodescritores. Um importante aspecto que se oculta atrás dessa instrução é a falsa noção de que há discursos neutros na linguagem humana. Confundindo neutralidade, objetividade e interpretação, muitos audiodescritores perdem a oportunidade de compartilhar suas próprias leituras, na ilusão de que "não estão interpretando", como se a própria compreensão e a leitura não fossem resultado da interpretação.

Neste bloco final trazemos a discussão para deixá-la como ponto de reflexão. A pergunta óbvia é: será que todos vêm a mesma coisa? Ao olhar uma nuvem, por exemplo, quantos diferentes olhares resultarão? Entendemos que a resposta está em saber justificar a interpretação, pois, a nosso ver, não existe linguagem neutra ou não interpretativa e acreditamos que evitar subestimar a capacidade cognitiva da pessoa com deficiência - o que é absolutamente correto - não deve se confundir com a privação da interpretação do audiodescritor, porque, como afirmamos, inexistem discursos sem interpretação. Muitas vezes, ao contrário, a PcDV pode enriquecer seu conhecimento enciclopédico e experienciar emoções estéticas ao partilhar da interpretação alheia.

É preciso saber observar, mediante letramento visual, a proposta que foi oferecida ao longo deste artigo, o qual procurou demonstrar que o ato de compartilhar a visão, em uma perspectiva de acessibilidade, carece de expertise do audiodescritor que, por sua vez, precisa observar certos procedimentos metodológicos sem prejuízo da capacidade intuitiva e da sensibilidade artística natural.

Com o auxílio das variadas ferramentas disponibilizadas pelas novas tecnologias, elaboramos e propusemos roteiros de audiodescrição aplicados à tradução do não verbal em verbal, tanto para a imagem artística estática (pintura) quanto para a imagem artística dinâmica (filme). Um produto multissemiótico como o cinema explora sons, músicas instrumentais, tomadas e ângulos especiais, jogos de luzes, efeitos que são agregados à ação e ao diálogo, de forma a construir significados planejados pelo diretor ou pelo autor da obra. Em nossa experiência, resultado de pesquisas qualitativas e quantitativas, os resultados estão mostrando que não basta descrever o que se ouve ou se vê na tela, é preciso conduzir a descrição de modo que ela permita ao deficiente visual desfrutar de um prazer estético.

A seleção linguística, que é fruto da percepção dos audiodescritores, traz um mundo concreto à PcDV e ativa dinamicamente as estruturas que são fixas nos limites da tela: "A língua cria uma narrativa dentro da obra e referencia o mundo exterior da obra ao nosso próprio mundo, para tentar captar algo de sua parte dinâmica" (HOLLAND, 2009, p. 182, tradução nossa). ${ }^{9}$

No âmbito do Grupo de Pesquisa Lead, vários trabalhos acadêmicos comprovaram a inexistência da "linguagem neutra", a exemplo de Praxedes e Magalhães (2013), que abordaram a questão à luz da Teoria da Avaliatividade, para concluir que não existe neutralidade na língua mesmo quando o falante, seguindo uma concepção positivista, acredita estar produzindo um discurso neutro.

Aderaldo (2014, p. 60), parodiando Schleiermacher (2011), ${ }^{10}$ propõe que o audiodescritor:

1) ou deixa o pintor o mais possível em paz e leva o espectador cego ao seu encontro, por meio da audiodescrição do tipo não interpretativa: 2) ou deixa o espectador cego o mais possível em paz e leva o pintor ao seu encontro, por meio de uma audiodescrição do tipo interpretativa.

Nas audiodescrições propostas, certas escolhas foram propositadamente interpretativas e até mesmo intrusas, em termos de Holland (2009). Por exemplo, quando informamos na $\mathrm{AD}$ que o retrato "parece uma fotografia naturalista", ou que a faixa branca "parece ser a gola de uma roupa interior" e que o "olhar enviesado se encontra com nosso olhar, como a convidar-nos a entrar na obra",

9 "The language creates a narrative within the piece, and makes reference outside the world of the work to our own world to try to capture some of the work's dynamic".

10 O autor é famoso por ter exposto o dilema do tradutor: "ou bem o tradutor deixa o escritor o mais tranquilo possível e faz com que o leitor vá a seu encontro, ou bem deixa o mais tranquilo possível o leitor e faz com que o escritor vá a seu encontro". 
estamos, conscientemente, modalizando a nossa própria dúvida, a modalidade epistêmica que igualmente nos assalta e que desejamos compartilhar esse sentimento de dúvida.

Da mesma forma, na AD fílmica estamos interpretando quando dizemos que, ao receber um embrulho selado, a jovem o abre "cuidadosamente". O uso do advérbio modal é uma forma de interpretar. "Pensativa, fecha o embrulho". A exemplo do narrador onisciente das obras literárias, nos atrevemos a interpretar que está "pensativa". Também assumimos nossa interpretação quando dizemos "olhar profundo, meio risonho e meio insinuante".

Como entende Holland (2009), uma "boa" audiodescrição de obra de arte deve permitir ao espectador relacionar-se com o objeto, pessoa ou pintura que se descreve de forma holística; isto significa integrar a descrição de maneira que se converta em parte da experiência artística, em lugar de manter essa experiência à distância, pois a descrição deve chegar à mente e ao coração.

\section{Considerações finais}

Este artigo focalizou a acessibilidade à arte visual no âmbito do lazer e cultura, porém ela também se faz necessária no campo do trabalho e da educação das pessoas com deficiência visual. Ao longo desta reflexão, desconstruímos a vaga instrução "descreva o que você vê", que circula entre certos audiodescritores, e evidenciamos a necessidade de instrumentalizar o audiodescritor, capacitando-o a fazer escolhas descritivas, bem como capacitando-o a explicá-las, adequando a audiodescrição ao escopo e ao público-alvo a que se destina.

\section{REFERÊNCIAS}

ADERALDO, M. F. Proposta de parâmetros descritivos para Audiodescrição à luz da interface revisitada entre tradução audiovisual acessível e semiótica social - multimodalidade. 2014. 206f. Tese (Doutorado em Estudos Linguísticos) - Faculdade de Letras da Universidade Federal de Minas Gerais, Belo Horizonte, 2014.

ADERALDO, M. F.; NUNES, M. S. A audiodescrição e a acessibilidade visual: breve percurso histórico. In: ADERALDO, M. F. Et al (Org.). Pesquisas teóricas e aplicadas em audiodescrição. Natal: Edufrn, 2016. Disponível em: <http://www.sedis.ufrn.br/bibliotecadigital/site/interativos.php>. Acesso em: 10 out. 2017.

ADORO CINEMA. Moça com brinco de pérola. Disponível em: $<$ http://www.adorocinema.com/filmes/filme-45323/>. Acesso em: 07 fev. 2016.

ALVES, R. Concerto para corpo e alma. Campinas, SP: Papirus, 1998.

ALVES, S; TELES, V. C; PEREIRA, T. Proposta para um modelo brasileiro de audiodescrição para deficientes visuais. Tradução \& Comunicação, n. 22, p. 9-29, 2011.

BRASIL. Presidência da República. Lei no 13.146, de 06 de julho de 2015. Institui a Lei Brasileira de Inclusão da Pessoa com Deficiência (Estatuto da Pessoa com Deficiência). Brasília, DF, 2015. Disponível em: < $\underline{\text { http://www. }}$ planalto.gov.br/ccivil_03/Ato2015-2018/2015/Lei/L13146.htm>. Acesso em: 20 fev. 2016.

Ministério da Cultura. Agência Nacional de Cinema (Ancine). Instrução Normativa 116, de 18 de de$\overline{\text { zembro }}$ de 2014. Brasília, DF, 2014. Disponível em: <http://www.ancine.gov.br/legislacao/instrucoes-normativas-consolidadas/instru-o-normativa-n-116-de-18-de-dezembro-de-2014>. Acesso em: 07 fev. 2015.

CHEVALIER, T. Girl with a pearl earring. London: Penguin, 1999.

GIRL with a pearl earring. Direção: Peter Webber. Intérpretes: Scarlett Johansson; Colin Firth. Roteiro: Olivia Retreed. Reino Unido/Luxemburgo, 2003. 1 DVD (100 min), color. Disponível em: <https://www.youtube.com/ watch? $\mathrm{v}=\mathrm{VbQQ1MjgD5s}>$. Acesso em: 24 jun. 2017.

HOLLAND, A. Audio description in the theatre and the visual arts: images into words. In: DÍAS-CINTAS, Jorge; ANDERMAN, Gunilla. Audiovisual translation: language transfer on screen. New York: Palgrave Macmillan, 2009.

JAKOBSON, R. On linguistic aspects of translation. In: VENUTI, Lawrence (Ed.). The translation studies reader. London: Routledge, 2000. p. 113-118. 
MAURITIHUS. Johannes Vermeer - Girl with a Pearl Earring. Disponível em: $<$ https://www.mauritshuis.nl/en/ discover/mauritshuis/masterpieces-from-the-mauritshuis/girl-with-a-pearl-earring-670/>. Acesso em: 29 jun. 2017.

MIANES, F. L. Consultoria em audiodescrição: alguns caminhos e possibilidades. In: CARPES, D. S (Org.). Audiodescrição: práticas e reflexões. Santa Cruz do Sul, RS: Catarse, 2016. p. 10-21.

MOTTA, L. M. V. M.; ROMEU FILHO, P. (Org.). Audiodescrição: transformando imagens em palavras. São Paulo: Secretaria de Estado dos Direitos da Pessoa com Deficiência, 2010.

O'TOOLE, M. A systemic functions of art. In: PETER, H. F.; GREGORY, M. (Ed.). Discourse in society: systemic function perspectives - meaning and choice in language: studies for Michael Halliday. Westport: Ablex Publ, 1995. p. 159-180.

. The language of displayed art. 2. ed. New York: Routledge, 2011.

PLAZA, J. Tradução intersemiótica. São Paulo: Perspectiva, 1987.

PRAXEDES FILHO, P. H.; MAGALHÃES, C. M. A neutralidade em audiodescrições de pinturas: resultados preliminares de uma descrição via teoria da avaliatividade. In: ARAÚJO, V. L. S.; ADERALDO, M. F. Os novos rumos da pesquisa em audiodescrição no Brasil. Curitiba: CRV, 2013. p. 83-87.

SCHLEIERMACHER, F. D. E. Dos diferentes métodos de traduzir. Princípios, Natal, v. 14, n. 21, p. 233-265, jan./jun. 2007. 